\title{
Virtual Synchronous Zoom On and Zoom Off : Combined with Engaging Media toward EFL Learners' Vocabulary Development
}

\author{
${ }^{1}$ Faizatus Sholihah \\ Email : faizatus_170403@umg.ac.id \\ Universitas Muhammadiyah Gresik \\ ${ }^{2}$ Slamet Asari \\ Email : asari70@umg.ac.id \\ Universitas Muhammadiyah Gresik
}

\begin{abstract}
Due to the popularity of online learning using zoom application which has been implemented by several educational circles in pandemic era, has showed several issues related to their virtual zoom learning. This study is aimed to investigate the efficiency of learning vocabulary using virtual synchronous zoom in collaboration with engaging media, by turning learners' video on and off. Pre-test and post-test with the same item and form of multiple choice questions were given to two different groups of 30 participants with the same duration of time, media and topic to measure EFL learners' vocabulary development using experimental design and was analyzed using several quantitative tests. 25 items of instruments used were tested based on their validity and reliability. Questionnaires of Thai and English language versions were filled in by EFL learners with the total of 10 items. The results showed that the 2 groups of EFL learners showed positive results in enhancing their vocabulary mastery, but the EFL learners' group who turned their video on had higher results compared to those who turned their video off. In addition, the EFL learners of zoom on group also experienced less difficulty and inconvenience during the virtual learning process.
\end{abstract}

Keywords : synchronous zoom, zoom on and zoom off, EFL learners, vocabulary development, engaging media.

\section{Introduction}

Zoom as virtual learning has become very familiar to be applied in this pandemic era. This popular application is mostly used by all levels of education, starting from primary level to higher college level. The use of zoom application to stay in touch via online with others as well as in learning communication between teachers and learners can be solution to replace face to face learning activities which can no longer be implemented with the aim of avoiding the addition of cases and accelerating the reduction of existing viruses' rates (Lenkaitis, Chesla Ann. 2020, Hong, Chiew. 2020). Due to the complexity of its features, zoom considered to be the most chosen application compared to other applications supported by its features such as slide-sharing, video, private and public chat, microphone, recording, and whiteboard.

Zoom Application and its complex features are also commonly used by learners to learn English, one of those is learning language component which is vocabulary. Vocabulary has an essential impact in English learning which can support learners' language skills, because the richer vocabularies the learners have, the more expert they will master the language (Hwang, G. 2019, Youssef, Ahmed 2020).

On the other hand, learning vocabulary is not as easy as people think. There are still many learners who face difficulties in vocabulary learning and do not have any satisfying progress in achieving their goals. As in fact, most of EFL learners are difficult in using effective language due to inadequate vocabulary knowledge which hinders the efficient use of language. However, the lack of adequate information about vocabulary makes EFL learners unrecognized to predict words meaning. This is mainly happened because they 
Published by English Language Education Department of UMG usually learn vocabulary by memorizing and directly looking up new word definitions of bilingual dictionary. At this point, learning vocabulary using memorization strategies can cause problems when learners have limited working memory capacity which lead them to loose information that has occurred (Cummins, J. et. al. 2017, Kuswari, Niken. et.al. 2019, Kabooha, R (2018), Maftoon, Hamidi, \& Sarem. 2018, Zarei \& Gilanian, 2019). Moreover, it also makes EFL learners difficult to guess the meaning of foreign language vocabulary without adequate contextual clues.

Therefore, it would be necessary to find solutions to help EFL learners learn vocabulary more easily and correctly based on the context (Prajapati, Ruby \& Chamundeshwari.2020). Adequate learning medias need to be used in students' vocabulary learning. Opportunities to engage in ICT-assisted vocabulary learning programs can encourage the learners to acquire word meanings effectively and efficiently. This will mainly be involved in various exercises, repeated questions in various forms, and EFL learners will have access to a convenient online system (Ko\&Goranson,2017, Kuswari, Niken. 2019).

However, many previous research showed that most teachers did not use ICT fully in the learning process. They use zoom application only to share power point slides, without being combined with other engaging and adequate media during their learning process. Some of them even also use zoom application for its whiteboard feature which can be considered too traditional and almost similar with face to face meetings if it is not combined with other media (Hosseini, Monresadat. 2020, Hong, Chiew. 2020). Other teachers use zoom application only as a formality for online learning, where the use it to share while explaining the learning material. This way teachers sometimes loose their focus on learners' learning interaction process, where most of the learners tend to turn their video and microphone then give no response during their learning process (Rahayu, 2020, Hong, 2020, Shukhri, 2020).

Previous studies on L2 vocabulary learning have neglected to examine how the application of zoom modalities can improve language learners' vocabulary learning and how the learners perceive this learning through the use of synchronous zoom and engaging media in the EFL context. There are also fewer studies on learners' attitude and perception towards the use of video in EFL classrooms using zoom application for their vocabulary learning. Consequently, this study is aimed to investigate whether the application of synchronous zoom by turning video on and off combined with engaging media can enhance EFL learners' English vocabulary learning. It also explores the EFL learners' perceptions towards the use of synchronous zoom in combination with engaging media on vocabulary learning during the virtual classroom.

\section{Research of vocabulary learning using virtual learning media}

Several previous research have showed that problems of EFL learners in using the language effectively due to inadequate vocabulary knowledge can be solved by implementing such kind of supporting learning media.

Tabar and Khodareza (2012) examined how media affects vocabulary learning for 60 intermediate and mid-level of Iranian learners. In this research, Vocaboly, the media program, was used in accordance as guidance from the teacher. They found that EFL learners have learned and retained significant greater language in compared to teacher-led groups through supporting engaging media. The results on vocabulary L2 have shown the relation between media and their L2 learning. In order to concentrate more on using the program as a tool for student independence in language training, the participation of the dominating instructor community in learning must therefore be reduced.

Boonkongsaen, Nathana \& Channarong Intaraprasert's study (2014) was intended at examining the influence on the use of VLSs by learners of Thai-tertiary level at the language learning fields. 905 Thai students from EFL in north-east Thailand were attended and VLS questionnaire was used as data collection. Data analysis including descriptive statistics, analysis of variance and chi-square tests have been carried out. The 
Published by English Language Education Department of UMG results revealed that study areas and prior language-learning experiences affected the use of students' overall VLS, the use of VLSs category, and the individual strategy levels. In relation to the two variables, the variance patterns of the VLS usage were noticed.

Alhamami, M (2014) explored the effectiveness of three vocabulary-teaching methods among Saudi learners' acquisition of English word meanings using technology in their L1. 99 EFL learners tried each of the three methods such as associating the words' meanings with relevant audios, images, and videos, in language laboratories. A lesson treatment to examine the effectiveness of the three treatments and a questionnaire to understand students' attitudes toward the three treatments were used as as the instruments. Statistically significant enhancement were found with the results of the lesson process revealed in the memorization of words associated with images but not words in audios or videos. The survey results indicated that students regard the image associative method as the most helpful, followed by the video associative method. The results of the treatment prove that once the meanings of the words are linked to images, they better remember the significance of the word in their L1.

Rahimi, Merak \& Allahyari, Ateefah (2019) investigated the effect of multimedia-assisted explanatory vocabulary learning (VLS) education in the use of foreign language learners' strategy and vocabulary learning for 40 participants. Prior to the study, participants were assessed with experimental design for vocabulary knowledge and the use of VLS. The research revealed that the two groups were distinctly higher. The VLS guidelines also showed that they greatly influence the study community's use of cognitive and memory strategies, though their intervention has not affected the use of meta-cognitive and convictive strategy.

Yawilaoeng, Rattana's study (2020) was aimed to know the effect of an English vocabulary video on L2 vocabulary learning by 25 college students at a Thai university. There have been five types of tests performed, including the English language analysis, pre-test, post-test, vocabulary videos, and questionnaire. The results of this study indicated a boost result in the post-test scores despite its use of English language video by Thai EFL students. Furthermore this results also revealed that after examining a video containing first-and second-language titles, images and audios were relevant to the target terms. EFL learners also have acquired L2 vocabulary information. In addition, the results showed that students of EFL preferred to use video to learn L1 and L2 vocabulary, with interesting associated images and also a rationalizing volume. The essential findings of this study thereby lead to theoretical and pedagogical implications for the crucial role played by learning media in connection with the visual-auditory knowledge. In addition, teachers need to consider the learners' interest in L1 and L2 contexts for the preparation of learning vocabulary resources.

Arifani, Yudhi (2020) examined the efficacy of incidental vocabulary learning for children at home using carton videos and explored their reactions on the application of the two separate variations, with and without captions. 14 male and 16 female with the total of 30 EFL children who had no English precedent were implemented using an at-home experimental design. A vocabulary knowledge scale (VKS) was applied to measure their additional enhancement of incidental vocabulary. The findings revealed that children who have learnt the same vocabulary through short cartoon videos with household captions for 30 minutes have been able to learn the same language more efficiently than children who have learnt the same vocabulary with untitled cartoon videos. EFL children also have positively reacted to two separate interventions in both groups which have no English precedent. Furthermore, the two gaps distinction results can be the focus of choice to decide vocabulary learning treatments in giving titled or untitled captions.

\section{Synchronous zoom as virtual media in vocabulary learning}

Synchronous online discussions are intended to facilitate communication and knowledge sharing among learners to exchange ideas about virtual learning by having discussion (Shukhri, Athirah. et.al. 2020). Furthermore, synchronous virtual classroom conferences will make learners feel more closely connected to their peers and teachers in a simulated learning activity that enables them to participate in spontaneous 
Published by English Language Education Department of UMG

discussions. They also can actively communicate as well as in direct meeting while the teachers can also assess their involvement which looks like in real time (Rahayu, Dwi. 2020). In addition, as if participants are in a face-to-face meeting, they will get direct feedback or answers to feel more related. Zoom, which provides real-time communication through a mixture of audio, video and chat, has given the learners opportunities to their peers and teachers. The conference tool video facilitates contact between teachers and students from different places in real sense. Teachers and students can even be enhanced in some way by chat from different locations and provide a virtual interactive learning experience (Lenkaitis, Chesla Ann. 2020).

Zoom is a synchronous teaching tool in which the use of visual and auditory modalities is seen as an effective way to improve L2 vocabulary learning which is considered very useful for learning EFL learners. Learning vocabulary through zoom that include images, sounds, written text, and videos can support message transfer in unique ways (Layali, Khaled \& Ahmed Al-Shlowiy. 2020). Zoom supports more opportunities in dealing with L2 where input from visual and auditory modalities is also used in language pedagogy because several modalities can improve memory better in language learning (Singh, Charanjit. 2020).

\section{Method}

\section{Research question}

This study focuses on the following two questions:

1. Will there be any significant differences toward the EFL learners' vocabulary development after having virtual synchronous zoom combined with engaging medias with video camera on compared to their mastery achieved with video camera off?

2. What are the learners' perception toward the application of virtual synchronous zoom on and zoom off combined with engaging medias?

\section{Design and Procedure}

An experimental design has been applied to compare EFL learners' vocabulary learning between two different group frameworks. In group A (zoom on), learners had a virtual class using zoom application combined with engaging media with an active video camera, and in group B (zoom off), learners had a virtual class with an unactivated camera. Both groups were given the same pre-test and post-test. Table 1 describes the research design.

\section{Table 1}

Research design

\begin{tabular}{|c|c|c|}
\hline \multirow{2}{*}{25 multiple choices } & Virtual Learning Treatment & Post-Test \\
\cline { 2 - 2 } & Group A (Zoom On) & \multirow{2}{*}{25 multiple choices } \\
\cline { 2 - 3 } & Group B (Zoom Off) & \\
\hline
\end{tabular}

The pre-test and final test were conducted online via Slideshare Zoom on 25 multiple choice vocabulary questions. Each meeting, online class using zoom combined with engaging media lasts for 30-40 minutes. This experiment was carried out for 14 meetings, starting from July to October 2020. The questions used in the pre-test and post-test were vocabulary questions from a combination of several topics about English and were tested based on their validity and reliability. The instruments were concluded as valid items 
Published by English Language Education Department of UMG

by showing 25 result items which are less than 0,05 and also were proven as quite high reliable by showing the Cronbach Alpha's result of 0,775. Online learning activities were combined with several medias such as pictures, videos, songs, and quizzes in the form of games. 6 topics were discussed in 12 meetings which focused more on learning vocabulary that they often encounter in their daily life. This test was tested on students from 2 different groups to determine the suitability of the targeted words.

\section{Settings and Participants}

The experiment was conducted online by involving 30 participants from EFL primary learners in area 2 Loei, Thailand. In this case the researcher is as a teacher who run the virtual classes, and made the learning materials. While the English teachers from Thai schools were in charge of overseeing the learning process. The online learning learners were divided into two groups. The first group consisted of 15 learners who became the experimental group that was treated by activating video camera (zoom on), and the second group with the same number of 15 participants as the control group which was treated by deactivating video camera (zoom off). Both groups received the same treatment in terms of material, topics, frequency and duration of learning for 14 meetings, including 12 meetings for learning activities and 2 meetings for pre-test and posttest activities. Teachers from Thai primary schools also agreed to the research plan. Teachers and learners also volunteered to help fill out the questionnaires that had been distributed previously. The teachers only helped distribute the questionnaire, without being involved to fill in the questionnaires. The questionnaires were given into two languages which were in English and Thai version. During learning activities, the teacher did not help the learners answer questions, but only helped with technical problems such as the internet connection. Therefore, EFL learners learned from virtual synchronous zoom naturally and independently.

\section{Finding and Discussion}

\section{Data Analysis}

The EFL learners' answers to the target vocabulary test were given in quiz questions which was being slideshared in zoom application. Pre-test and post-test questions consisted of 25 multiple choice questions. Descriptive statistics are used to see the distribution of data and the average score. One sample t-test was used to see the development of vocabulary knowledge for each group. Finally, to draw comparisons between the performance levels of the experimental and control groups, independent sample t-test was also used. Meanwhile, an attitude survey questionnaire was distributed to teachers of each group to describe learners' responses to the acceptance of virtual zoom learning combined with engaging media.

Results

Prior to answer the research questions, the normality and homogeneity tests were carried out using One-Sample Kolmogorov-Smirnov Test and Shapiro Wilk-Test. Two forms of normality test were carried out in order to prove the normality's validity of the two sample groups. Since the study sample consisted of only 30 participants, the Shapiro Wilk-Test was added to test specifically for normality results in analyzing a small number of participants less than 50 .

Table 2 illustrates the normality group statistical calculations between learners' vocabulary learning with virtual synchronous zoom learning combined with engaging medias by turning learners' video on and off. The results illustrate that the data from the two groups are normally distributed due to the significance values of 0,122 based on Kolmogorov-Smirnov Test, while Shapiro-Wilk Test shows the significance value of 0,172 and 0,90 . Both of those tests' results can be concluded as normally distributed by showing the significant values which are more than 0.05 .

Table 2

Normality test 
Published by English Language Education Department of UMG

\section{Tests of Normality}

\begin{tabular}{|cl|r|r|r|r|r|r|}
\hline \multirow{2}{*}{} & \multirow{2}{*}{ Groups } & \multicolumn{3}{|c|}{ Kolmogorov-Smirnov $^{\mathrm{a}}$} & \multicolumn{3}{c|}{ Shapiro-Wilk } \\
\cline { 2 - 8 } & Statistic & \multicolumn{1}{c|}{ Df } & \multicolumn{1}{c|}{ Sig. } & \multicolumn{1}{c|}{ Statistic } & \multicolumn{1}{c|}{ df } & \multicolumn{1}{c|}{ Sig. } \\
\hline \multirow{2}{*}{ Scores } & Group A (Zoom On) & .197 & 15 & .122 & .917 & 15 & .172 \\
& Group B (Zoom Off) & .197 & 15 & .122 & .898 & 15 & .090 \\
\hline
\end{tabular}

a. Test distribution is Normal.

Table 3 calculates the homogeneity statistical calculation of the two groups. So that, the homogeneity of the two groups has been achieved as equal data by showing the significant values of 0.401 which are more than 0,05 .

Table 3

Homogeneity test

Test of Homogeneity of Variance

\begin{tabular}{|l|r|r|r|r|}
\hline & Levene Statistic & df1 & df2 & \multicolumn{1}{c|}{ Sig. } \\
\hline Based on Mean & .654 & 1 & 28 & .425 \\
Based on Median & .714 & 1 & 28 & .405 \\
Based on Median and with & .714 & 1 & 27.895 & .405 \\
adjusted df & & & & \\
Based on trimmed mean & .726 & & & .401 \\
\hline
\end{tabular}

Table 4 compares the mean scores of the two different groups. The mean gain of the two different groups is described below:

\section{Table 4}

The mean scores of the two groups

Descriptive Statistics

\begin{tabular}{|l|r|r|r|r|r|}
\hline & $\mathrm{N}$ & Minimum & Maximum & Mean & \multicolumn{1}{c|}{ Std. Deviation } \\
\hline Pre-Test (Zoom On) & 15 & 40.00 & 64.00 & 55.4667 & 7.06972 \\
Post-Test (Zoom On) & 15 & 64.00 & 96.00 & 77.3333 & 9.15475 \\
Pre-Test (Zoom Off) & 15 & 40.00 & 64.00 & 55.2000 & 8.02852 \\
Post-Test (Zoom Off) & 15 & 56.00 & 84.00 & 71.2000 & 8.16963 \\
Valid N (listwise) & 15 & & & & \\
\hline
\end{tabular}

It was found that EFL learners who learn vocabulary using synchronous zoom combined with engaging media by turning their video on (zoom on group) achieved average scores of 55.46 in the pre-test with standard deviation of 7.060, while their post-test mean score was 77.33 with standar deviation of 9.15. In contrast, students who learn vocabulary using synchronous zoom combined with engaging media with 
Published by English Language Education Department of UMG turning their video off (zoom off group) achieved the mean score of 55.22 in Pre-Test with standar deviation of 8.02, while the mean score of the Post-Test mean was 71.20 with Standar deviation of 8.16.

Meanwhile, table 5 depicts the results of an independent sample t-test of the two groups. The results are shown below:

\section{Table 5}

Independent t-testresults

\section{Independent Sample T-Test}

\begin{tabular}{|c|c|c|c|c|c|c|c|c|c|}
\hline & $\begin{array}{r}\text { Levene's } \\
\text { Equality of }\end{array}$ & $\begin{array}{l}\text { est for } \\
\text { ariances }\end{array}$ & \multicolumn{7}{|c|}{ t-test for Equality of Means } \\
\hline & & & \multirow[b]{2}{*}{$\mathrm{t}$} & \multirow[b]{2}{*}{ Df } & \multirow{2}{*}{$\begin{array}{l}\text { Sig. }(2- \\
\text { tailed) }\end{array}$} & \multirow{2}{*}{$\begin{array}{c}\text { Mean } \\
\text { Differenc } \\
\mathrm{e}\end{array}$} & \multirow{2}{*}{$\begin{array}{c}\text { Std. Error } \\
\text { Differenc } \\
\mathrm{e}\end{array}$} & \multicolumn{2}{|c|}{$\begin{array}{c}95 \% \text { Confidence } \\
\text { Interval of the } \\
\text { Difference }\end{array}$} \\
\hline & $\mathrm{F}$ & Sig. & & & & & & Lower & Upper \\
\hline $\begin{array}{l}\text { Equal variances } \\
\text { assumed }\end{array}$ & \multirow[t]{2}{*}{.473} & \multirow[t]{2}{*}{497} & \multirow[t]{2}{*}{2.181} & \multirow[b]{2}{*}{26.968} & \multirow[t]{2}{*}{.038} & 6.66667 & 3.05713 & .40442 & 12.92891 \\
\hline $\begin{array}{l}\text { Equal variances } \\
\text { not assumed }\end{array}$ & & & & & & 6.66667 & 3.05713 & .39361 & 12.93973 \\
\hline
\end{tabular}

From the table above it can be seen clearly that the level of significance (sig. 2 - tailed) shows 0.038 which is less than 0.05 . The result, provides convincing evidence that null hypothesis is rejected at $5 \%$ level, while the $\mathrm{Ha}_{1}$ is accepted. This can be explained by the fact that there is a significant difference between learners' coincidence vocabulary scores based on different treatments. Statistics show that learners who learn vocabulary using virtual synchronous zoom combined with engaging medias by turning the video camera (zoom on group) score higher than those learners who learn vocabulary using virtual synchronous zoom by turning their video off (zoom off group) with the same time duration, media, and learning topics.

English and Thai questionnaires which were given into two languages version were distributed to the learners in the final learning after the post-test took place. The questionnaires were about the perception of learners' experience during virtual learning using zoom combined with engaging media for 14 meetings and were done around 30 until 40 minutes for each meeting. The ten-item questions containing the elements of positive and negative statements were filled in.

Table 6 reveals the results of these questions explaining how learners' perception toward their virtual learning using zoom combined with engaging media. The results are shown below:

\section{Table 6}

Learner's perception of virtual synchronous zoom combined with engaging media.

\begin{tabular}{|c|l|c|c|}
\hline No. & \multicolumn{1}{|c|}{ Statements } & Zoom On & Zoom Off \\
\hline 1. & $\begin{array}{l}\text { Learners enjoy the virtual synchronous zoom } \\
\text { learning combined with engaging medias }\end{array}$ & $78,6 \%$ & $73,3 \%$ \\
\hline
\end{tabular}


Vol. 5, No. 1; February 2021

Published by English Language Education Department of UMG

\begin{tabular}{|c|c|c|c|}
\hline & & & \\
\hline 2. & $\begin{array}{l}\text { Learners are more motivated to learn more because } \\
\text { of the combination of games, videos, quizzes, and } \\
\text { song }\end{array}$ & $90,6 \%$ & $78,6 \%$ \\
\hline 3. & $\begin{array}{l}\text { Learners can learn vocabularies using } \\
\text { games, videos, quizzes, and song. }\end{array}$ & $86,6 \%$ & $68,8 \%$ \\
\hline 4. & $\begin{array}{l}\text { Learners get improvement in } \\
\text { vocabulary learning through virtual } \\
\text { synchronous zoom. }\end{array}$ & $73,3 \%$ & $70,6 \%$ \\
\hline 5. & $\begin{array}{l}\text { Learners can learn more vocabularies using } \\
\text { zoom application with camera on (zoom on). }\end{array}$ & $70,6 \%$ & $65,3 \%$ \\
\hline 6. & $\begin{array}{l}\text { Learners are bored and not excited in virtual } \\
\text { synchronous zoom learning combined with } \\
\text { engaging medias. }\end{array}$ & $38,6 \%$ & $52,0 \%$ \\
\hline 7. & $\begin{array}{l}\text { Learners are more interested and motivated when } \\
\text { the video camera is off (zoom off) }\end{array}$ & $33,3 \%$ & $52,0 \%$ \\
\hline 8. & $\begin{array}{l}\text { Learners feel more difficult and confused in } \\
\text { learning using virtual zoom combined with } \\
\text { engaging medias }\end{array}$ & $33,3 \%$ & $45,3 \%$ \\
\hline 9. & $\begin{array}{l}\text { Learners are not focused when the camera video is } \\
\text { turned off (zoom off) }\end{array}$ & $85,3 \%$ & $65,3 \%$ \\
\hline 10. & $\begin{array}{l}\text { Learners gain nothing from the virtual synchronous } \\
\text { zoom classes }\end{array}$ & $22,6 \%$ & $42,6 \%$ \\
\hline
\end{tabular}

The mean results of the questionnaire revealed that the two groups of learners' vocabulary learning with virtual synchronous zoom combined with engaging medias by turning their video on and off responded positively. Learners who learned vocabulary with zoom on virtual synchronous zoom combined with engaging media had a higher average score than those learners who learned vocabulary with virtual synchronous zoom off combined with engaging media. The average score of the first group is 79,94 and the second group becomes 71.32. Therefore, it can be concluded that virtual synchronous zoom combined with engaging medias with or without turning on their video can enhance their vocabulary mastery.

In addition, the average score of respondents on the negative aspect of using virtual synchronous zoom on and zoom off combined with engaging medias in learning vocabulary also shows results which are 42.62 for virtual zoom on and 51,44 for virtual zoom off. Both groups agreed that learning vocabulary by zooming on and zooming off virtual combined with media was attractive to them, but the zoom off group had a higher results in the inconvenient aspects regarding to the unactivated video.

\section{Discussion}

This study has explored EFL learners' vocabulary learning using two different treatments of turning video on and off during virtual synchronous zoom application learning combined with engaging media. Vocabulary learning is extremely considered hard and tedious by EFL students because they are accustomed to do direct translation using a Thai-English bilingual dictionary. Both groups which were treated using the same time duration, topic, and media had done their pre-test and post-test. They were tested using some stages 
Published by English Language Education Department of UMG

of quantitative data method. At the end of the experiment, a questionnaire was given to EFL learners to draw their responses of virtual vocabulary learning.

These findings show that learners who learn vocabulary through synchronous zoom combined with engaging medias improved to a higher level when they join the virtual meeting by turning their video on rather than turning it off. It can be seen from the research mean score results that shows 77.33 for group A (zoom on group), and 71.20 for group B (zoom off group). As a result, enhanced vocabulary learning through zoom combined with engaging media by turning video on is a viable alternative for EFL learners to enhance their mastery of vocabulary learning.

The combination of engaging media which were implemented using synchronous zoom application greatly attract learners' motivation to learn vocabulary broader. It is proven from the questionnaire result which shows both of two groups agreed that they were more motivated if those engaging medias were combined in their virtual learning with the result of 90,6\% from Group A (zoom on) and 78,6\% from Group B (zoom off).

In contrast to previous studies that mostly discussed about vocabulary learning with zoom application where teachers only focused on explaining material without focusing on video interaction between teachers, learners, or their peers, this study provides new knowledge, about the effect of activating video cameras in online learning using zoom. The learners' focus and motivation in learning are essential matters that affect learning enhancement results. This can be seen from the effect of turning their video on and off that is taking place. It is proven from the questionnaire's result that shows learners of Group A (zoom on) has a higher focus, motivation, and enjoyment with the result of 79,9 compared to the learners of Group B (zoom off) with the result of 71,32 .

Turning off video during virtual learning process can interfere the focus of learners, where in this situation the teacher cannot know the exact learners do, as well as the learners who cannot know their peers and teachers. This situation can lead them to learning boredom when the learning activities take quite a long time. Learners' boredom that continues to be experienced in learning, will affect their motivation to take part in learning with a disturbed focus. It also can affect them in getting the maximum material, and will have an impact on their vocabulary learning results. Furthermore, learners boredom can lead them to face inconvenience feeling during the learning process, decrease their learning motivation to learn more and hard to control their focus as learning progresses. It can be seen from the questionnaire result that shows learners of Group A (zoom on) that has less difficulties and inconvenient feeling during the virtual learning with the result of $42.62 \%$, compared to the learners of Group B (zoom off) with the result of 51.44\%.

\section{Conclusion}

This study offers in-depth empirical support for the potential of vocabulary learning for EFL learners through virtual synchronous zoom combined with engaging media. The findings of this study also have curricular benefits. Virtual learning using zoom application with video on much more contributes in enhancing the mastery of EFL learners, EFL teachers can also emphasize more on the focus of students' learning interaction between learners to their peers, learners to their teachers, and activities that are actually carried out by students when learning activities take place. Focusing at the learners exact do needs to be done by monitoring them to keep turning their video on during the virtual learning, so that the class can be more controlled to get maximum results and achieve the learning objectives. The combination of engaging media in online learning also should be applied by teachers to enhance learners' motivation and interest during the learning process. 
Alhamami, Munassir. 2014. Vocabulary Learning through Audios, Images, and Videos : Linking Technologies with Memory. Computer-Assisted Language Learning Electronic Journal. Vol 17 (2) p 87-112.

Al-Maliki, Moza. 2020. Quizlet : An Online Application to Enhance EFL Foundation Students' Vocabulary Acquisition at Rustaq College of Education, Oman. Arab World English Journal. Vol 6. p 332- 343.

Arifani, Yudhi. 2020. Cartoon Video-Assisted Learning : An Investigation into the Acquisition of EFL Children's Incidental Vocabulary. Computer-Assisted Language Learning Electronic Journal. Vol 21 (2), p 17-31

Boonkongsaen, Nathana \& Channarong Intaraprasert. 2014. Use of English vocabulary learning strategies by Thai tertiary-level students in relation to fields of study and language learning experiences. English Language Teaching Journal, Vol 7(5), p 59-70.

Cummins, J. et. al. 2017. The effectiveness of texting to enhance academic vocabulary learning: English language learners' perspective. Computer Assisted Language Learning, Vol 30(8) p 816-843.

Dhawan, Shivangi. 2020. Online Learning : A Panacea in the Time of Covid-19 Crisis. Journal of Educational Technology. Vol 49 (1) p 5-22.

Destianingsih, Arita. et.al. 2020. Investigating Students' Need for Effective English Online Learning During Covid-19 for Polbeng Students. English and Language Teaching Lectura Joournal. Vol 7 (2).

Hong, Chiew. 2020. Communicative Language Teaching (CLT) through Synchronous

Online Teaching in English Language Preservice Teacher Education. International Journal of TESOL Studies. Vol 2 (2) p 62-73.

Hosseini, Monresadat. 2020.The effect of Online Interpretations via Interactive White Boards on Vocabulary Learning. Interdisciplinary Journal of Virtual Learning. Vol 5 (1) p 68-79.

Kabooha, R 2018. The effects of YouTube in multimedia instruction for vocabulary learning: Perception of EFL students and teachers. English Language Teaching Journal, Vol 11(2), p 72-81.

Kuswari, Niken. et.al. 2019. Exploring the Effects of Using Game on Students' Vocabulary Mastery : A Case Study in Instructional Material and Media Development Class. Advances in Social Science, Education and Humanities Research. Vol 4 p 34.

Layali, Khaled \& Ahmed Al-Shlowiy. 2020. Students' Perception of E-Learning for ESL / EFL in Saudi Universities at Time of Corona Virus : A Literature Review. Indonesian EFL Journal. Vol 6 (2)

Lenkaitis, Chesla Ann. 2020. Recorded Video Meetings in Virtual Exchange : A new Frontier for Pre-service Teacher's Reflection. Journal of Virtual Exchange. Vol 3. p 33-39

Mardiah, Henny. 2020. The use of E-Learning to Teach English in the Time of Covid-19 Pandemic. English Teaching and Linguistic Journal. Vol 1 (2) p 49-55.

Prajapati, Ruby \& Chamundeshwari.2020. Effective Vocabulary Learning Strategies Using Computer Assistes Language Learning. Gedrag and Organizatie Review. Vol 33. p 147. 
Published by English Language Education Department of UMG

Rahayu, Dwi. 2020. Synchronous Zoom Web Conference System : An Exploratory Study on Students' ELearning Experience. Journal of ELT Research. Vol 5 (1) p 68-79.

Rahimi, Merak \& Allahyari, Ateefah. 2019. Effect of Multimedia Learning Combined with Strategy-Based Instruction on Vocabulary Learning and Strategy Use. SAGE Open. Vol 9(2).

Ramezanali, N. et.al. 2019. Vocabulary Learning and Retention through Multimedia Glossing. Journal of Language Learning \& Technology, Vol 23(2), p 105-124.

Shukhri, Athirah. et.al. 2020. UniKL Students' perception on synchronous learning using ICT as learning tools to learn English. Journal of Critical Reviews. Vol 7, Issue 8.

Singh, Charanjit. et. al. 2020. Rethinking English Language Teaching through Telegram, WhatsApp, Google Classroom, and Zoom. Multifaceted Review Journal. Vol 11 (11) p 45-54.

Tabar, Khodareza, M. 2012. The effect of using multimedia on vocabulary learning of pre-intermediate and intermediate Iranian EFL learners. Journal of Basic and Applied Scientific Research, Vol 2(12)

Yawilaoeng, Rattana. 2020. Second Language Vocabulary Learning from Viewing Video in an EFL Classroom. Canadian Center of Science and Education. Vol 13 (7).

Youssef, Ahmed Fathy. 2020. The effectiveness of Corpus Based Approach on Vocabulary Learning Gains and Retention in Saudi Tertiary EFL Context. Journal of English Language Teaching and Applied Linguistics. Vol 2 (3). 